\title{
EFEITO TÓXICO DE ADUBOS POTÁSSICOS NO DESENVOLVIMENTO DE MUDAS DE GUARANAZEIRO (1)
}

\author{
VICTOR PAULO DE OLIVEIRA (2), RÚTER HIROCE (3) \\ E MARCO ANTONIO MILAN BOAVENTURA (2)
}

\begin{abstract}
RESUMO
Efeitos de diferentes doses de cloreto e de sulfato duplo de potássio e magnésio foram estudados no crescimento de mudas de guaranazeiro cultivado em Latossolo Roxo em condiçōes de casa de vegetação. Utilizaram-se as doses de zero, dois, quatro, oito, dezesseis e trinta e dois gramas de $\mathrm{K}_{2} \mathrm{O}$ por planta. Os efeitos foram avaliados através de sintomas nas folhas, altura da planta, diâmetro do caule, número de folhas simples e compośtas, número de plantas sobreviventes, peso seco da folha, caule e raiz. $O$ cloreto de potássio mostrou, a partir da dose de 6,66g por planta, ser mais tóxico do que o sulfato duplo de potássio e magnésio.
\end{abstract}

Termos de indexação: guaranazeiro, Paullinia cupana H.B.K., adubos potássicos, toxicidade.

(1) Trabalho apresentado no XX Congresso Brasileiro de Ciência do Solo, realizado em Belém, PA, de 14 a 21 de julho de 1985. Recebido para publicação em 21 de janeiro de 1985.

(2) Seção de Plantas Tropicais, Instituto Agron6́mico (IAC), Caixa Postal 28, 13001 Campinas (SP).

(3) Seçāo de Fertilidade do Solo e Nutrição de Plantas, IAC. 


\section{INTRODUÇĀO}

Em condiçōes de campo, têm sido registrados vários casos de "queima" de plantas pela aplicação no solo de elevadas quantidades de adubos ou de adubos com elevados índices salinos. Em condições de casa de vegetação, foram feitos estudos comparativos entre diferentes doses de cloreto e sulfato de potássio com cafeeiro (FURLANI, 1973), batatinha (FURLANI et alii, 1977) e feijoeiro (FURLANI et alii, 1978), tendo o cloreto se mostrado mais tóxico do que o sulfato em doses equivalentes de potássio.

O presente trabalho visou conhecer os efeitos de diferentes doses de cloreto e de sulfato duplo de potássio e de magnésio sobre o desenvolvimento de mudas de guaranazeiro, Paullinia cupana 'Sorbilis'.

\section{MATERIAL E MÉTODOS}

O ensaio foi instalado em condiçōes de viveiro no Centro Experimental de Campinas, Instituto Agronômico, em Latossolo Roxo, cuja análise química de uma amostra revelou os seguintes resultados: $\mathrm{pH}=5,2 \mathrm{em} \mathrm{CaCl}$; matéria orgânica $=5,4 \% ; \mathrm{P}=97 \mu \mathrm{g} / \mathrm{ml} ; \mathrm{em}$ meq $/ 100 \mathrm{~cm}^{3}$ de solo: $\mathrm{K}^{+}=0,08 ; \mathrm{Ca}^{2+}=5,1$; $\mathrm{Mg}^{2+}=0,6 ; \mathrm{H}^{+}+\mathrm{Al}^{3+}=3,4$. A análise ffsica revelou argila $=44 \%$, limo $=2 \%$ e areia $=54 \%$, sendo classificado como argilo-arenoso, segundo a classificação textural da Sociedade Brasileira de Ciência do Solo.

O delineamento experimental constou de onze tratamentos com sete repetições, tendo sido utilizada uma muda por parcela (saco de polietileno de cor preta com $7,6 \mathrm{~kg}$ de solo). Foi utilizado o cultivar Sorbilis, progênie PTVR1-6. Todos os tratamentos receberam cerca de $0,5 \mathrm{~g}$ de nitrogênio por parcela, distribuido mensalmente durante os sete meses de duração do ensaio. Não foram aplicados adubo fosfatado e calcário.

Os tratamentos foram organizados conforme o quadro 1.

Os fertilizantes foram incorporados ao solo úmido, procedendo-se semanalmente, a seguir, à imigação individual de cada vaso. As mudas utilizadas possulam cerca de quatro meses de idade, após transplante, e apresentavam quatro folhas simples, quando foram submetidas aos diferentes tratamentos.

Durante o ensaio, foram anotados os seguintes parâmetros: aparecimento de sintomas de fitotoxicidade, altura da muda, diâmetro do caule, número de folhas simples e compostas, nota estipulada em função do aspecto da parte aérea e do sistema radicular, número de plantas sobreviventes e peso seco da folha mais caule e da raiz. 
QUADRO 1. Tratamentos utilizados por planta

\begin{tabular}{|c|c|c|c|}
\hline \multirow{2}{*}{ Tratamento } & \multirow{2}{*}{$\begin{array}{c}\text { Dose de } \\
\mathrm{K}_{2} \mathrm{O}\end{array}$} & \multicolumn{2}{|c|}{ Fontes de potássio } \\
\hline & & $\left({ }^{1}\right)$ & $(2)$ \\
\hline no & & g & \\
\hline 1 & 0 & - & - \\
\hline 2 & 2 & - & 9,09 \\
\hline 3 & 4 & - & 18,18 \\
\hline 4 & 8 & - & 36,36 \\
\hline 5 & 16 & - & 72,73 \\
\hline 6 & 32 & - & 145,45 \\
\hline 7 & 2 & 3,33 & - \\
\hline 8 & 4 & 6,66 & - \\
\hline 9 & 8 & 13,32 & - \\
\hline 10 & 16 & 26,64 & - \\
\hline 11 & 32 & 53,28 & - \\
\hline
\end{tabular}

$\left({ }^{1}\right)=\mathrm{KCl} . \quad\left({ }^{2}\right)=\mathrm{K}_{2} \mathrm{SO}_{4} \cdot 2 \mathrm{MgSO}_{4} \cdot$

\section{RESULTADOS E DISCUSSÃO}

Pelo quadro 2 , nota-se que somente a testemunha e os tratamentos que receberam dose 1 de sulfato duplo e de cloreto de potássio não provocaram sintoma de fitotoxicidade nas folhas das mudas. A dose 2 de sulfato duplo $(18,18 \mathrm{~g})$, embora afetasse ligeiramente as folhas, não provocou a morte de mudas. O cloreto de potássio mostrou-se mais tóxico do que o sulfato duplo de potássio e magnésio, em especial a partir da dose de $4 \mathrm{~g}$ de $\mathrm{K}_{2} \mathrm{O}$ por muda.

Ainda no quadro 2 , nota-se que a altura final da muda aos 225 dias foi afetada pelas doses 4 e 5 de sulfato duplo e a partir da dose 2 de cloreto de potássio. Em relação ao diâmetro do caule da muda, somente as doses 1 e 2 do sulfato duplo de potåssio e magnésio proporcionaram desenvolvimento superior à testemunha.

Pelo quadro 3, observa-se que os tratamentos 2 e 3 (doses 1 e 2 de sulfato duplo de potássio e magnésio) apresentaram maior número de folhas compostas, maior peso seco do caule, folha e raiz, sendo o efeito benéfico das doses confirmado por avaliaçōes visuais por sistema de notas para a parte aérea e sistema radicular. 
QUADRO 2. Aparecimento de sintomas de fitotoxicidade 48 horas após a aplicação das doses; número total de mudas sobreviventes; altura média inicial, final e percentagem na variação de crescimento e diâmetro final

\begin{tabular}{|c|c|c|c|c|c|c|}
\hline \multirow{2}{*}{ Tratamento* } & \multirow{2}{*}{$\begin{array}{l}\text { Grau de } \\
\text { sintomas }\end{array}$} & \multirow{2}{*}{$\begin{array}{c}\text { Mudas } \\
\text { sobreviventes }\end{array}$} & \multicolumn{3}{|c|}{ Altura das mudas } & \multirow{2}{*}{$\begin{array}{l}\text { Diâmetro final } \\
\text { das mudas }\end{array}$} \\
\hline & & & Inicial & 225 dias & $\%$ & \\
\hline $\mathrm{n}^{\mathrm{o}}$ & & & $\longrightarrow$ & $-\mathrm{cm}$ & & $\mathrm{cm}$ \\
\hline 1 & Nenhum & 7 & 6,21 & 8,86 & 43 & 0,33 \\
\hline 2 & Nenhum & 7 & 6,07 & 9,43 & 55 & 0,44 \\
\hline 3 & Leve em 3 mudas & 7 & 5,65 & 9,14 & 62 & 0,43 \\
\hline 4 & Forte em 1 muda & 6 & 5,93 & 9,42 & 59 & 0,27 \\
\hline 5 & Moderado em 4 mudas & 3 & 5,86 & 7,00 & 19 & 0,22 \\
\hline 6 & Moderado em 6 mudas & 1 & 5,74 & 8,00 & 39 & 0,19 \\
\hline 7 & Nenhum & 7 & 6,07 & 9,65 & 59 & 0,33 \\
\hline 8 & Leve em 6 mudas & 1 & 6,49 & 8,50 & 31 & 0,32 \\
\hline 9 & Moderado em 5 mudas & 0 & 5,71 & - & - & - \\
\hline 10 & Queima total & 0 & 5,64 & - & - & - \\
\hline 11 & Queima total & 0 & 6,07 & - & - & - \\
\hline
\end{tabular}

$* 1$ = testemunha; $2,3,4,5$ e $6=2,4,8,16$ e $32 \mathrm{~g}$ respectivamente de $\mathrm{K}_{2} \mathrm{O}\left(\mathrm{K}_{2} \mathrm{SO}_{4} \cdot 2 \mathrm{MgSO}_{4}\right) ; 7,8,9,10 \mathrm{e}$ $11=2,4,8,16$ e $32 \mathrm{~g}$ respectivamente de $\mathrm{K}_{2} \mathrm{O}(\mathrm{KCl})$.

QUADRO 3. Número de folhas simples (NFS), número de folhas compostas (NFC), nota para a parte aerea (NPA), nota para o sistema radicular (NSR), peso seco de folhas mais caule (PSFC), peso seco de raiz (PSR) e peso seco total (PST) aos 225 dias após a aplicação das doses

$\begin{array}{lllll}\text { Tratamento NFS NFC NPA NSR } & \text { PSFC PSR PST }\end{array}$

\begin{tabular}{|c|c|c|c|c|c|c|c|}
\hline \multirow[b]{2}{*}{ Testemunha } & \multicolumn{4}{|c|}{$-\mathrm{n}^{\circ}$} & \multirow[b]{2}{*}{9,6} & \multirow[b]{2}{*}{5,9} & \multirow[b]{2}{*}{15,5} \\
\hline & 6,1 & 0,1 & 0,7 & 1,1 & & & \\
\hline $\mathrm{KMgSO}_{4}-1$ & 6,7 & 1,1 & 2,0 & 2,1 & 20,4 & 11,9 & 32,3 \\
\hline $\mathrm{KMgSO}_{4-2}$ & 6,6 & 1,0 & 1,7 & 1,9 & 23,0 & 13,9 & 36,9 \\
\hline $\mathrm{KMgSO}_{4}-3$ & 6,3 & 0,2 & 1,2 & 1,2 & 10,9 & 4,8 & 15,7 \\
\hline $\mathrm{KMgSO}_{4}-4$ & 6,0 & 0 & 0,3 & 1,0 & 1,2 & 1,5 & 2,7 \\
\hline $\mathrm{KMgSO}_{4}-5$ & 5,0 & 0 & 0 & 0 & - & - & 0,4 \\
\hline $\mathrm{KCl}-1$ & 6,4 & 0,4 & 0,9 & 1,3 & 10,8 & 5,3 & 16,1 \\
\hline $\mathrm{KCl}-2$ & 6,0 & 0 & 1,0 & 2,0 & - & - & 2,3 \\
\hline $\mathrm{KCl}-3$ & - & - & - & - & - & - & - \\
\hline $\mathrm{KCl}-4$ & - & - & - & - & - & - & - \\
\hline $\mathrm{KCl}-5$ & - & - & - & - & - & - & - \\
\hline
\end{tabular}




\section{CONCLUSÕES}

Os resultados obtidos permitiram tirar preliminarmente as seguintes conclusões:

1. O efei to benéfico do $\mathrm{K}_{2} \mathrm{O}$ só pôde ser observado com o uso do sulfato duplo de potássio e magnésio no aparecimento de folhas compostas - parâmetro desejável;

2. O cloreto de potássio, a partir da dose de $6,66 \mathrm{~g}$ por muda, mostrou-se mais tóxico às mudas de guaranazeiro do que o sulfato duplo de potássio e magnésio em doses equivalentes de $\mathrm{K}_{2} \mathrm{O}$;

3. Estudos mais detalhados de doses de $\mathrm{K}_{2} \mathrm{O}$ para o guaranazeiro deverão ser realizados, tendo por base $2 \mathrm{~g}$ do elemento.

\section{SUMMARY}

\section{EFFECTS OF SEVERAL RATES OF POTASSIUM CHLORIDE AND POT ASSIUM AND MAGNESIUM DOUBLE SULPHATE APPLIED IN POTTED "GUARANÄ" (PAULLINIA CUPANA H.B.K.) SEEDLINGS}

Effects of several rates of potassium chloride and potassium and magnesium double sulphate in potted "Guarana" (Paullinia cupana H.B.K.) seedlings, growing in a Latosolic B "Terra Roxa" soil in greenhouse conditions were studied. The experimental design was in randomized blocks with eleven treatments and seven replications. Data were obtained for the following variables: toxicity symptoms; number of surviving plants; plant height; stem diameter; number of single, composite and total leaves; plant top and root dry weight; visual evaluation for the top plant parts and root system. Based on these data it was stablished the plant response and the degree of toxicity for the several rates of fertilizer applied.

Index terms: Paulinia cupana H.B.K., potassium fertilizers, toxicity symptoms.

\section{REFERÊNCIAS BIBLIOGRÁFICAS}

FURLANI, A.M.C. Efeitos da aplicação de cloreto e de sulfato de potássio na nutrição do cafeeiro (Coffea arabica "Catuar). Piracicaba, Escola Superior de Agricultura "Luiz de Queiroz", 1973. 63p. Dissertação (Mestrado - Mimeografado)

; HIROCE, R.; ANGELOCCI, L.R.; RAIJ, B. van; FURLANI, P.R. \& GROHMANN, F. Desenvolvimento e nutrição do feijoeiro em função da aplicação de doses de cloreto e de sulfato de potássio. Ciência e Cultura, São Paulo, 30(7):855-863, 1978 .

; TEIXEIRA, J.P.F.; GALLO, J.R. \& MIRANDA FILHO, H. da S. Efeitos da aplicação de doses crescentes de cloreto e de sulfato de potássio na nutrição e produção da batatinha (Solanum tuberosum 'Bintje'). Ciência e Cultura, São Paulo, 29(2):193-199, 1977. 